\title{
MULTI-SCALAR SURVEYS FOR COMPLEX ARCHITECTURES
}

\author{
D. Palomba ${ }^{1}$, M. Campi ${ }^{1}$, V. Cirillo ${ }^{2}$, A. di Luggo ${ }^{1}$, M. Facchini ${ }^{1}$, R. Iaderosa ${ }^{1}$, D. Iovane ${ }^{1}$ and O. Zerlenga ${ }^{2}$ \\ ${ }^{1}$ Department of Architecture University of Naples Federico II Via Forno Vecchio n.36, 80134 Napoli, Italy - (daniela.palomba, \\ massimiliano.campi, antonella.diluggo, marco.facchini, domenico.iovane)@unina.it - rosina.iaderosa92@gmail.com, \\ 2 Department of Architecture and Industrial Design, University of Campania Luigi Vanvitelli, Via San Lorenzo - Abazia di San \\ Lorenzo, 81031 Aversa (CE), Italy - (vincenzo.cirillo, Ornella.ZERLENGA)@ unicampania.it
}

\section{Commission II}

KEY WORDS: photogrammetric techniques, 3D reconstruction, Cultural Heritage, Point clouds, multi-scalar surveys

\begin{abstract}
:
This study is part of a much wider project in which professors and researchers from the University of Naples Federico II and the University of Campania Luigi Vanvitelli are collaborating in different subject areas. The object of study is the ancient Sanctuary of Montevergine characterized by a long history of transformations and stratifications. Driven by the desire to fill a singular gap, linked to the lack of a systematic and comprehensive study of a complex whose first settlement dates back to the early $12^{\text {th }}$ century, various studies have been started relating to the historical, artistic and architectural aspects.

Various surveying techniques and methods had to be used due to its architectural, compositional and settlement characteristics. Integrated 3D surveying technologies were used for both the cognitive studies of the entire complex as well as for investigating and detecting the elements at different scales, ranging from the architectural to the detailed ones.
\end{abstract}

\section{INTRODUCTION}

This paper presents the preliminary results of a recently started research project involving a team of researchers who have studied the Sanctuary of Montevergine.

The consolidated experience acquired, along with the various experiments related to studies and surveys on complex architectures, led the research group to start cognitive processes on the imposing monument. Despite the notoriety of the complex and the long history that characterises it, there seems not only to be a documentary and bibliographic void on the place but also a lack of any updated surveys and graphic representations. With a view to trying to fill this void, at least in part, significant campaigns have been started, carried out at different scales, with the aim of documenting and investigating the site, the architecture and the rich heritage housed in it.

The monastic complex of Montevergine rises on the Partenio Massif in the Campania Apennines, on the mountain from which the Sanctuary takes its name. The abbey stands at about two hundred metres from the summit, behind a rocky cliff from which it dominates the valley, while overlooking the small town of Mercogliano.

This context is made up of connections of volumes, transformations and stratifications in which the relationship with the context that houses it can only but significantly influence its configuration. The Marian complex has two basilicas: the ancient one, which sacrifices an entire side nave in favour of the new and majestic basilica built in the last century. There are two cloisters, the upper and lower one, lined by the rooms intended for the monks and placed at two different heights so as to accommodate and follow the natural slope of the mountain. Other buildings describe and surround the churchyard, characterized by the panoramic terrace, along with the high and steep $17^{\text {th }}$ century staircase that leads to the ancient basilica.

\section{OBJECTIVES OF THE STUDY: A MULTI-SCALAR APPROACH}

In this context, it was decided to carry out a double cognitive approach. The first linked to the need and way to acquire and manage an enormous amount of data and the second that orientated the study on the critical and comparative reading of the data deriving from the use of the different digital technologies.

Without doubt, in these areas, there was the need to define the level of detail of the artefact, a decision closely connected to the accuracy of the data and their use.

The objective of the study to carry out surveys with different levels of complexity, as well as various dimensions, is supported by the use of the photogrammetric survey technology.

The multi-scalar approach allows both to build a rich digital database, which can be consulted and used for different purposes as well as in different contexts, and provide data upon which to reason critically. These compared with the data acquired through active optical sensors, allow not only to evaluate and verify the accuracy of the data in terms of metric precision but also to consider other factors such as the costs of the instrumentation used as well as the times of acquisition processors needed. All these parameters needed to be fully considered in the planning and execution phases of a cognitive activity that was expressed through the surveys.

\section{METHODOLOGY}

Different 3D reality-based surveying technologies were used, based on both range-based and image-based surveying techniques (Dominici et al., 2017).

The choice of technologies was conditioned by the architectural features as well as the accessibility of the site. The wide range of sensors and technologies currently available for the surveying of morphometric and geometric data, which make the 
acquisition of high-precision 2D and 3D metric information possible, allowed for the creation and management of photorealistic three-dimensional models of the complex.

The most appropriate performances and solutions were evaluated in order to elaborate a survey as well as a general representation of the complex, which made multi-scalar representations and analyses possible (Callieri et al., 2011).

The surveying campaign was divided into two distinct phases. A first one used active sensors for the acquisition of morphometric data of the internal environments, and a second one which used passive sensors for the acquisition of the external components, also characterized by parts that are either difficult to access and/or are completely inaccessible.

\subsection{The laser scanner survey}

The laser scanner used to survey the Montevergine monastery complex was a FARO Focus3D S120 series produced by the manufacturer FARO.

It is a medium-range panoramic laser scanner, equipped with a sensor with a measurement range of the nominal distance between $60 \mathrm{~cm}$ and 120 metres, an accuracy in the distance measurement of the order of $\pm 2 \mathrm{~mm}$ at 25 metres and an angular resolution of $0.009^{\circ}$.

The vertical field of view is $305^{\circ}$, while the horizontal field is $360^{\circ}$ and the acquisition speed is 976.000 points $/ \mathrm{sec}$.

The laser scanner is part of the ranging scanner family and calculates the distance between the transmitter and the object detected by comparing the phase of the emitted signal with respect to that received.

In the case study, the internal environments surveyed with this Reality-Based technology included: the chapel of the Madonna, the ancient Basilica, the new Basilica dated 1952, the chapel of the Schiodazione and all the connecting environments. In addition, the upper and lower cloister as well as the churchyard with the panoramic terrace and the imposing staircase that leads to the ancient Basilica.

In total, 112 scans were carried out over three days (figure 1).

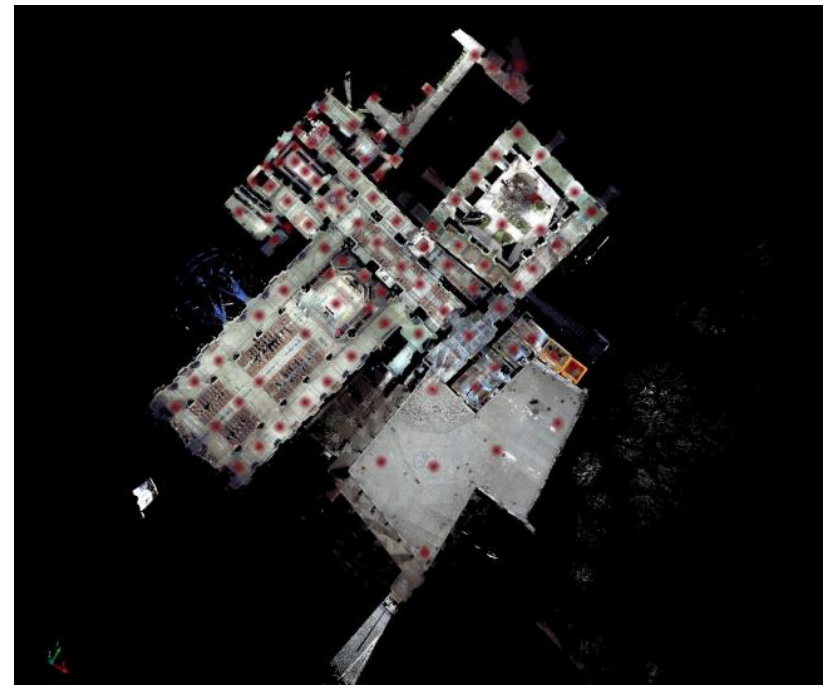

Figure 1. Distribution of laser scanner scanning points.

The scanning points were identified to both capture as many details as possible of the region of the building affected by the single scan as well as minimize as much as possible the shadow areas generated by any elements in the way of the laser.
Many of the aforementioned scans were started remotely, connecting the scanner in wi-fi mode to a smartphone with an android system, so as to allow for the recording of the survey data without any interference from the operator.

In this way, and not only, all the scans acquired were oriented according to the same reference system, so that an appropriate area of overlap between adjacent scans and the consequent recognition of common points through which to perform spatial roto-transactions was guaranteed.

Most of the roto-translations, which were particularly interesting in the Montevergine complex, took place automatically in the software; recognizing as presumed points, the presumed common points, plan and spherical targets, which, in particular the flat ones, were necessary to continue the survey phases in the following days.

The positioning operation, as well as all the processing and cleaning phases of the scans took place using the proprietary laser scanner software, Faro Scene.

The processing operations, carried out in about 6 hours, were carried out in a single work environment dividing the 112 scans into 4 clusters, three for the internal environments and one for the external ones.

The Faro Scene software was also used to obtain all the floor plans at the various altitudes as well as the vertical sections arranged in different planes, necessary for the analysis and understanding of the complex morphology of the sanctuary (figure 2).

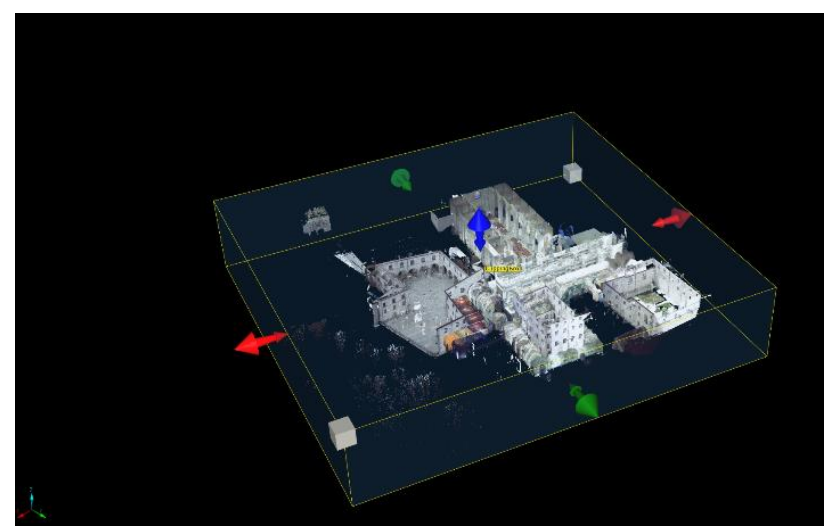

Figure 2. Clippingbox for section extrapolation (Faro Scene software)

\subsection{The photogrammetric survey}

The external components of the complex were surveyed using advanced methodological techniques, with passive sensors that allowed for the recording of photographic data through terrestrial and aerial acquisitions.

Specifically, the system of the roofs and elevations of the existing building was investigated.

For the multi-faceted and articulated roofing system, the photographic datasets were acquired with a drone, a Phantom 4 Pro Plus brand DJI equipped with a photographic camera with a 20 mega-pixel CMOS 1Inch sensor.

The choice to acquire the images from drones was dictated by the environmental conditions of the site, along with the extension and orography and the numerous inaccessible areas.

The risers, facing the courtyard with the imposing staircase leading to the church, saw the application of a terrestrial telescopic photogrammetric system equipped with an HCAO6 Black GoPro actioncam CMOS 12 mega-pixel camera. 
This equipment was used due to not only the articulation of the building but also the constant presence of visitors to the site. The acquisition and registration of the photographic data did not change the normal, daily use of the site.

The aerials photographs were taken of the whole site, with five automated flights being carried out at a constant height of 60 metres from the floor of the internal courtyard with a staircase leading to the church and the acquisition of 454 datasets (figure $3)$.

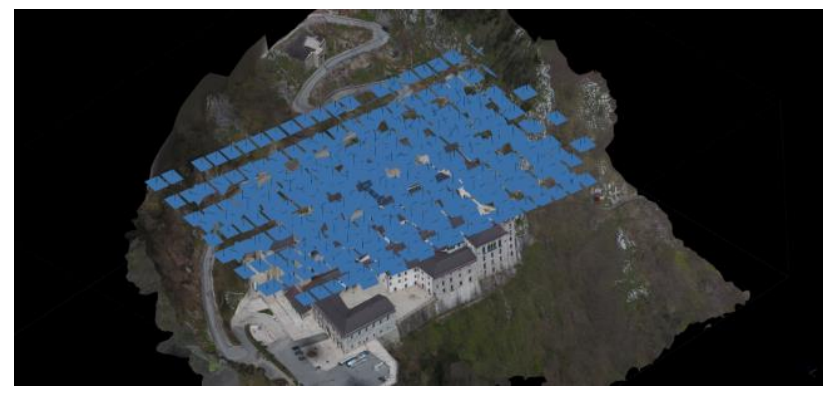

Figure 3. Acquisition of photographic datasets

The frames were acquired with an overlap, along the $\mathrm{X}$ axis, of about $80 \%$ and a sidelap, along the $\mathrm{Y}$ axis, of about $40 \%$ with a constant focal length of $20 \mathrm{~mm}$. Moreover, the acquisition phase included the recording of the photographs for the parallel axes, with the camera in the zenithal position downwards, and for the remaining part with the converging axes, with the camera inclined at about $45^{\circ}$ with respect to the dominant plane so as to allow for a correct construction of the three-dimensional polygonal model of the complex.

The recording of the photographic datasets for the risers was carried out in a continuous shooting mode with a total acquisition of 1,890 datasets (figure 4).

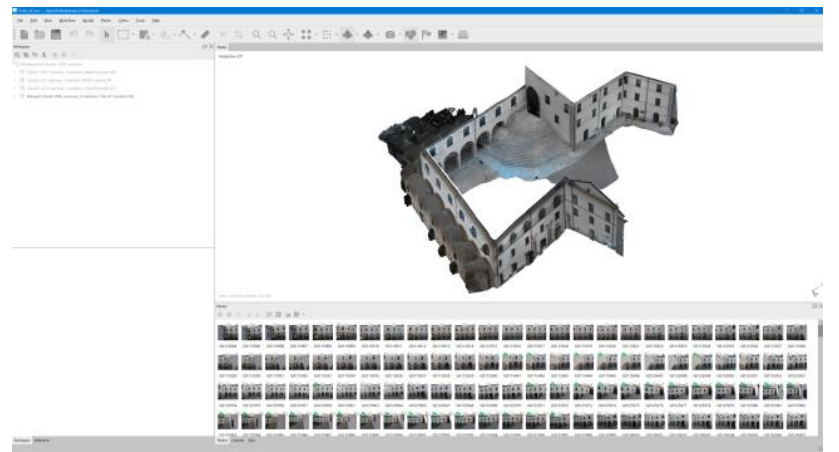

Figure 4. Metashape texture model.

The frames were acquired with an overlap, along the $\mathrm{X}$ axis, of about $60 \%$ and a sidelap, along the $\mathrm{Y}$ axis, of about $30 \%$ with a constant focal length of $15 \mathrm{~mm}$. The recording of the photographs for the parallel axes had the axis of the camera in a position perpendicular to the facades; for the converging axes, with the axis of the camera inclined at different angles; for the corners of the facades and the remaining parts of the parallel axes, with the axis of the camera in a zenithal position towards the floor.

As reported in the introduction, the shooting of the frames was carried out with the support of a telescopic pole which made it possible to record the data at different altitudes between 1 and $8 \mathrm{~m}$.
The photographs were taken at different heights and remotely via a smartphone installed on the pole. It was controlled through a special "GoProApp" application with which it was also possible to set the parameters of the room and view the photographs taken (figure 5). The drone and terrestrial images were processed with the Agisoft Metashape Professional Structure from Motion application, with the same processing operations being carried out for both photographic datasets (Inzerillo et al, 2013).

The work carried out allowed to obtain:

- a photorealistic model of the entire monastic complex resulting from the processing of 400 frames organized in a single project and subdivided into 01 chunks;

- a photorealistic model of the internal system of the facades resulting from the processing of 1792 frames organized in a single project and subdivided into 04 chunks.
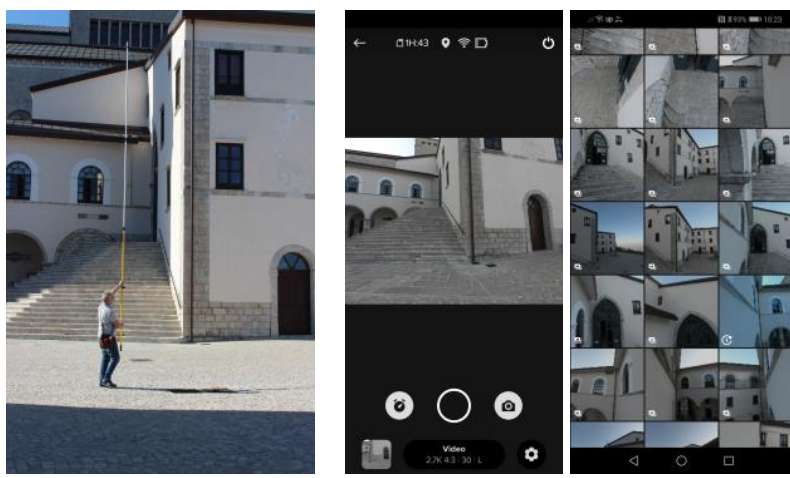

Figure 5. Mode of acquisition and recording of photographic datasets (Telescopic pole/GoPro App)

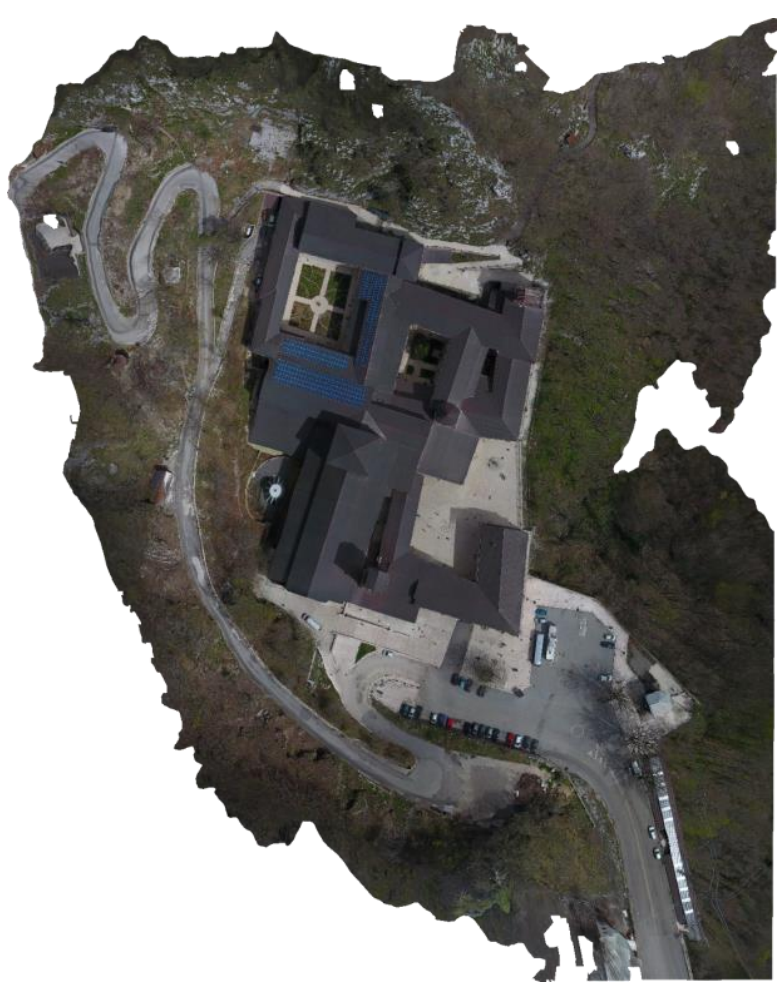

Figure 6. Zenith orthophoto of the Montevergine complex 


\subsection{Comparison of the techniques}

In this study, the elaborated point clouds, recorded through different acquisition phases, were also used to compare and analyse the metric data deriving from different technologies (Grilli et al., 2019).

The comparison was carried out through a critical and direct analysis of the processed data, along with the use of specific software with which the metric data of the different point clouds were examined and compared (Bastonero et al, 2014).

The processing of the data acquired in the survey phases produced two distinct point clouds, obtained from two different survey methods, which have been referenced to the same reference system.

The first obvious difference is in the quality of the data collected.

The laser scanner data are more detailed and accurate than those of the photogrammetric survey, however the chromatic quality of the latter is superior and much closer to reality.

Upon closer observation, the photogrammetric points cloud is denser and more defined in those hidden points where the laser, due to the morphology of the instrument itself, drags the shadow cones of the objects into the foreground.

To compare and calculate the metric differences between the two point clouds, it was decided to export both, from the software in which the processing took place, into .las format and import them, using the "drag and drop" method, into the opensource software Cloudcompare (figure 7).

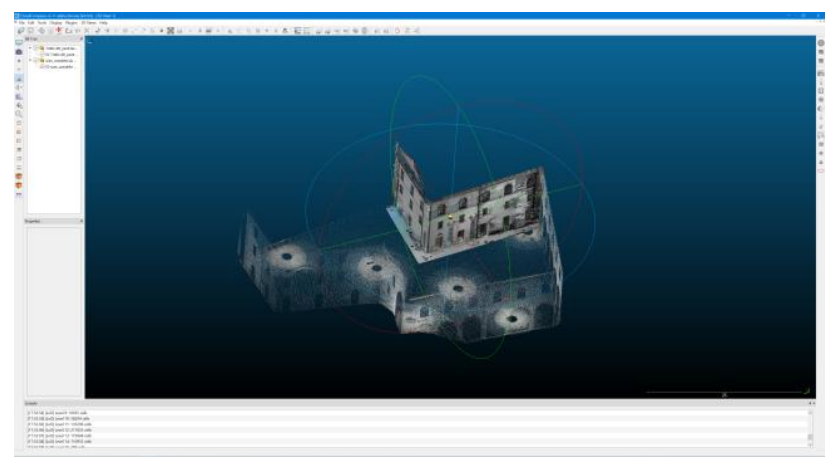

Figure 7. Import of laser scanner and photogrammetric clouds inside the Cloudcompare software

Inserting them one at a time, the clouds were automatically overlapped by the programme, thus confirming the correct referencing of the data.

To further reduce programme processing times, it was decided to eliminate any noise elements from the laser scanning cloud that were deemed unsuitable and unnecessary for the comparison (Farella et al, 2019).

Through the Cloudcompare software, the distance calculation can be carried out using two different methods: cloud-cloud distances and cloud-mesh distances.

To carry out the direct comparison between three-dimensional dense point clouds, the software is based on the "Structure Octree" technique, a tree-like structure.

In this case, it was decided to compare the clouds obtained from different methodologies using the cloud-cloud distances method, whereby each point of the cloud compared is compared to the closest point of the reference cloud, with its Euclidean distance being calculated.

In order to carry out this function, it is best that the reference cloud is of a high density, so as to be able to correctly identify the points examined, and make sure that the reference cloud is wider than the cloud to be compared.

For this reason, it was decided to use the laser scanner survey as a reference cloud (figure 8).

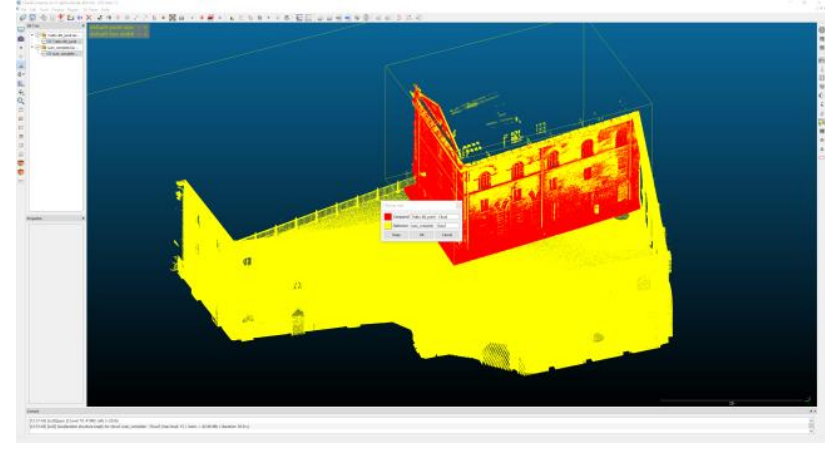

Figure 8. Cloud comparison using cloud-cloud distance method., the laser scanner cloud used as a reference in yellow and the photogrammetric cloud in red

Once the process is started, the programme calculates the initial approximate distances.

Leaving the setting of the basic parameters, considered congruous to the objective set by the study, the process for the effective computation of the distance between the clouds was continued.

The result obtained was a "statistical" estimate, in which, for deviation intervals, a histogram represents the number of points belonging to each deviation interval between the two clouds.

In graphical terms, the comparison cloud will appear coloured in a RGB colour scale, which goes from blue to red, passing through green, depending on the deviation that is between the points of the two clouds (figure 9).

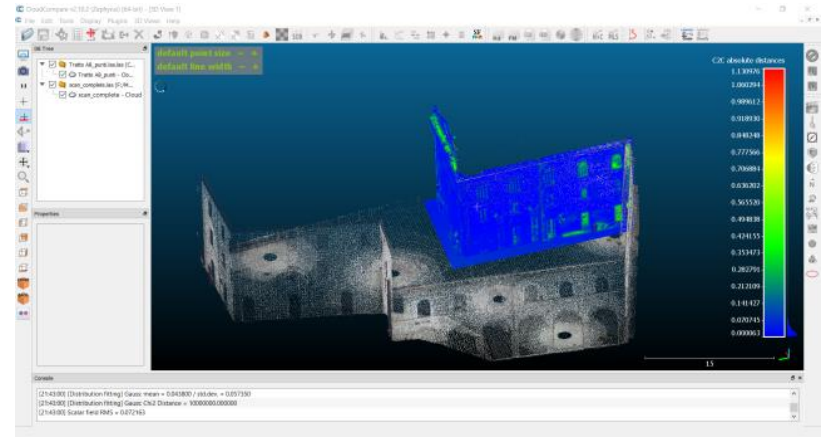

Figure 9. In RGB scale, portion of the model representing the average deviation of each point

A critical first glance of the image shows how the most distant points between the two clouds are those belonging to the 
windows and cornices, while the main surfaces of the facades have given excellent results.

This is probably due to the greater reliability of the surfaces perpendicular to the shooting direction.

As can be clearly seen in the histogram, the statistical distribution of the points analysed shows that most of them fall within the range of error between 0 and $0.05 \mathrm{~m}$.

Furthermore, by means of a Gauss function, to estimate the mean of the deviations and the standard deviation, an average distance between the point clouds of about $0.044 \mathrm{~m}$ and a standard deviation of about $0.057 \mathrm{~m}$ is obtained (figure 10).
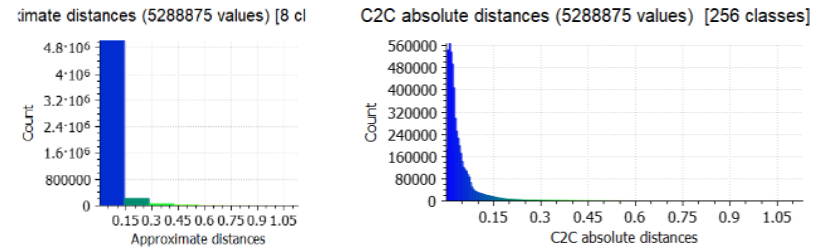

Gauss: mean $=0.043800 /$ std. dev. $=0.057350$ [2300 classes $]$

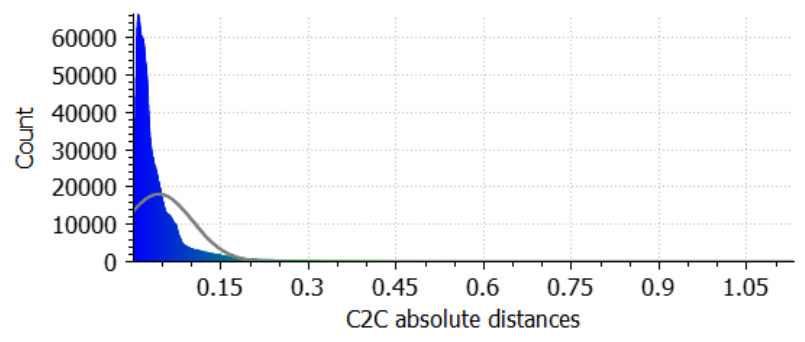

Figure 10. Comparison graphs

\section{THE PHOTOGRAMMETRIC SURVEY FOR THE DETAIL}

The sanctuary houses within its museum an important collection of objects that tell of the various transformations and modifications of the site. Therefore, a survey on a detailed scale could not not be done and then carried out in order to document the most representative testimonies. Given the large number of objects in the museum collection, which have recently been put on display, three different finds were chosen as a sample, which in terms of shape, size and materials were considered suitable for the case study phase: the wooden "Abbey seat" by local Campani carvers, in carved and painted wood, dating from the 12th/13th century, the "Sarcophagus of Bertrand and Jean de Lautrec" by an unknown Florentine artist from the second quarter of the 14th century and one of the many archaeological remains, the tombstone of "Achilles and Penthesilea", Roman art, dating from the second quarter of the 3rd century. The survey techniques used included the application of digital photogrammetric methods, specifically Structure from motion with Agisoft Metashape Professional, with the same processing operations being used for the various artefacts (Lo Brutto et al, 2011).

The photogrammetric technique is able to provide, at any application scale, accurate and detailed three-dimensional information as well as render the generated models computerized. The photogrammetric $3 \mathrm{D}$ reconstructions are aimed at creating mapping, three-dimensional, conservation, digital restoration, monitoring activities, visualization and animation documents (Angás et al., 2019).

Furthermore, this survey method was also necessary due to the environmental conditions of the various objects, as well as the fact that they are impossible to move due to their respective masses/weight.

The photographic data sets were acquired through the use of an actioncam, a GoPro Hero6 Black and a Canon EOS1300D reflex camera.

Given the limited size and low weight of the actioncam, the use a telescopic pole made it easy to take the various photographs by checking the correct overlap and sidelap, with a constant focal length of $15 \mathrm{~mm}$.

This camera set-up was used for the wooden seat and the sarcophagus.

In the first case study, 469 frames were recorded and processed with the determination of a three-dimensional polygonal model consisting of a Dense Cloud of approximately 16,195,476 points and the generation of a Build Mesh consisting of $1,079,697$ faces and 556,041 vertices as well as the determination of photorealistic texturized models (figure 11).

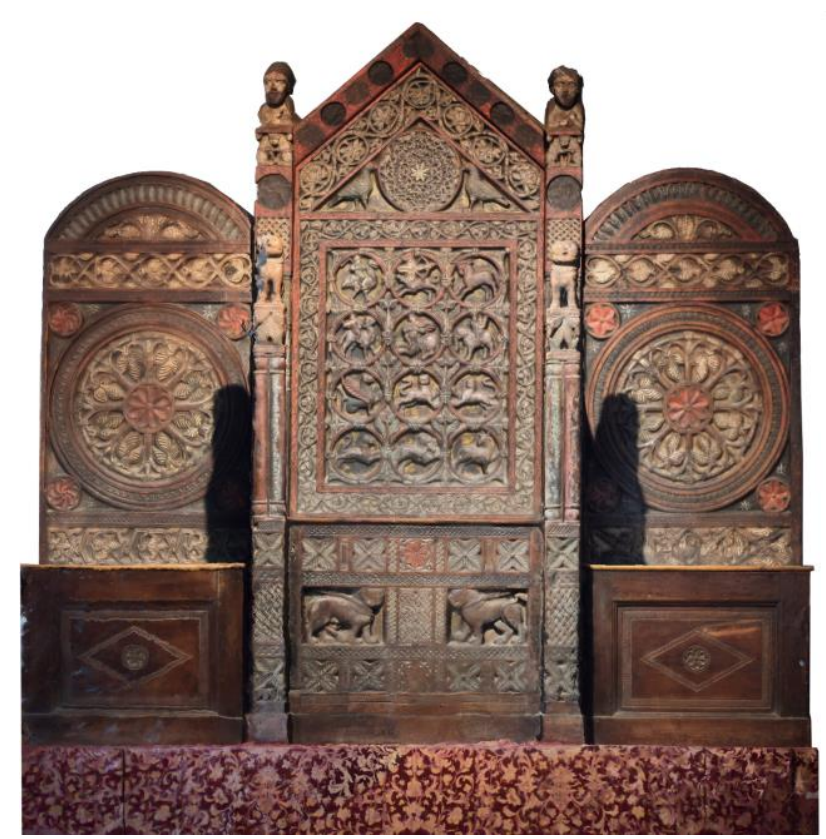

Figure 11. Orthophoto of the Seat

In the second case study, 469 frames were recorded and processed with the determination of a three-dimensional polygonal model consisting of a Dense Cloud of approximately $8,875,492$ points and the generation of a Build Mesh consisting of 2,159,785 faces and 1,053,391 vertices as well as the determination of photorealistic texturized models (Figure 12).

The third case study, the remains of the tombstone of "Achille and Pentesilea", included the recording of 227 datasets through the use of the reflex camera, always verifying the right overlapping of the frames. The acquisition operations were carried out moving parallel to the object, with the parallel axis technique, in order to facilitate the extraction of the textures as well as convergent axis grips, aiming at about $45^{\circ}$ with respect 
to the dominant plane in order to fill any areas not taken previously as well as any possible distortions of the model. The model obtained consists of a Dense Cloud of about $4,733,267$ points and the generation of a Build Mesh consisting of 946.653 faces and 474.417 vertices as well as the determination of photorealistic texturized models (figure 13).

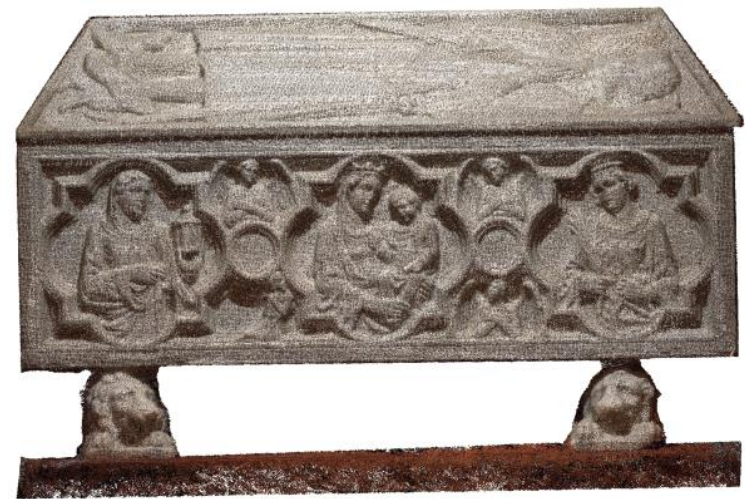

Figure 12. Dense Cloud
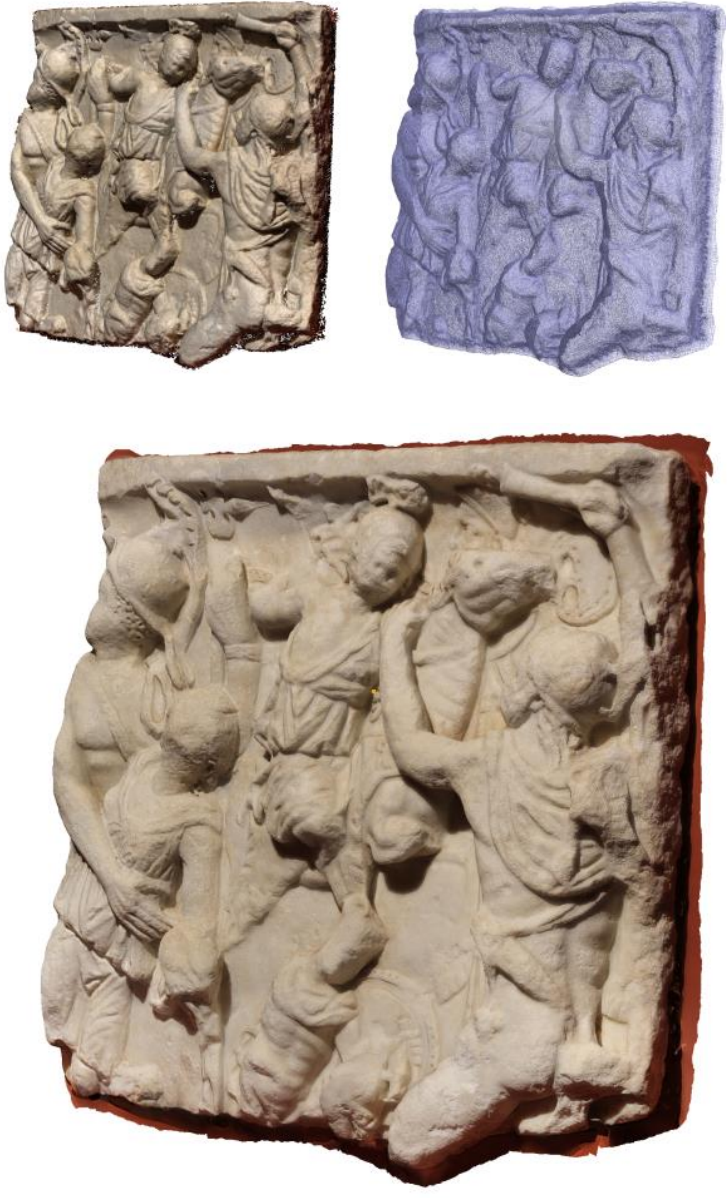

Figure 13. Metashape models (Dense Cloud, Mesh, Texture)

\section{RETURN METHODOLOGIES AND GRAPHIC REPRESENTATION}

The integrated digital survey of the basilica complex of Montevergine resulted in a methodology of reading that can be implemented through differentiated levels and different scales of representation, reporting elaborates capable of evaluating the $\mathrm{n}$ dimensions of the articulated system of the architectural artefact.

The restitution process in a CAD environment (still in progress) took place mainly through the use of orthophotographs obtained from specific planimetric and altimetric sections realized directly on the point clouds model. In this sense, the first critical process can be traced back to the design of the horizontal and vertical section planes, capable of: returning the articulated distribution of the Sanctuary in the form of planimetric and altimetric graphic representations; identifying and describing the main characteristics and different architectural styles present; obtaining a graphic representation of the various planimetric dimensions useful for visualizing the three main altimetric levels on which it stands.

Once the appropriate sectional plans of the 3D digital model were established, the corresponding orthophotos were obtained. This process was useful to carry out the total restitution of the Sanctuary in a greater percentage. To a lesser extent, however, it was necessary to integrate and critically interpret some of the architectural elements from photographs: both those taken in situ during the survey campaign and those taken from the laser scans (figure 14).
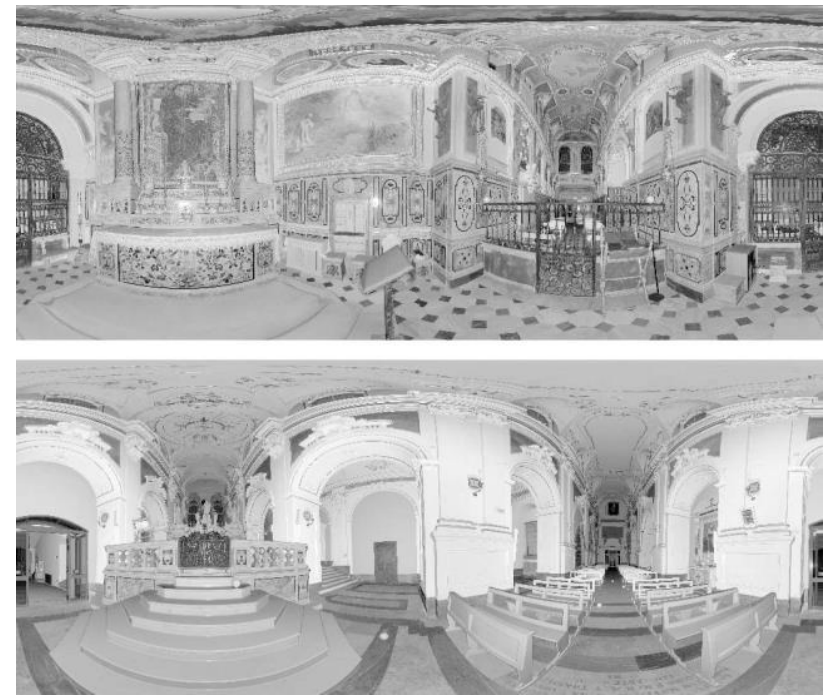

Figure 14. Equirectangular photographs taken by the laser scanner

This integration method was particularly useful for the spatial understanding of the building with the consequent representation of the internal environments, and even better, of the architectural elements that characterize them, especially in cases where the scanner had not acquired the information of the geometric breakpoints of the walls, pillars or altars leaning against the walls or, in the case where in the scan, there was a 
redundancy of information that prevented a simple critical reading.

To date, three main planimetries that show the three elevations over which the Sanctuary develops have been obtained. The first planimetric section illustrates the representation of the entrance hallway that leads onto a large courtyard closed on three sides and open on the east side with a panoramic view. The courtyard is bordered to the north by the walls of the Sanctuary and to the south-west by an irregularly shaped portico, punctuated to the south by a single series of bays and to the west by a double series. The latter, in the final part to the north, is inserted onto a polygonal entrance staircase that leads into the building.

The second planimetric section, which is on an intermediate level, registers in terms of size the largest planimetric development of the Sanctuary. Inside the latter, the main cloister and the two basilicas oriented by different development directions can be seen: the first and oldest, with an east-west longitudinal development axis; the second and more recent, with a north-south longitudinal development direction. Both basilicas were conceived with a spatial layout with three naves, and from a first graphic analysis of the plant, it is clear that the naves of the oldest basilica have taken on a completely different spatial configuration over time. Currently, the side nave to the north houses the Chapel of the Madonna of Montervergine, while the south aisle has been sacrificed to place a connection from the ancient basilica to the new one.

The third and final planimetric section, in addition to showing the articulation of the choirstalls and adjacent chapels of the ancient church (located at a higher altitude), also represents the second cloister located to the north-west (figure 15). Finally, the altimetric sections were returned with the same operating methodology.

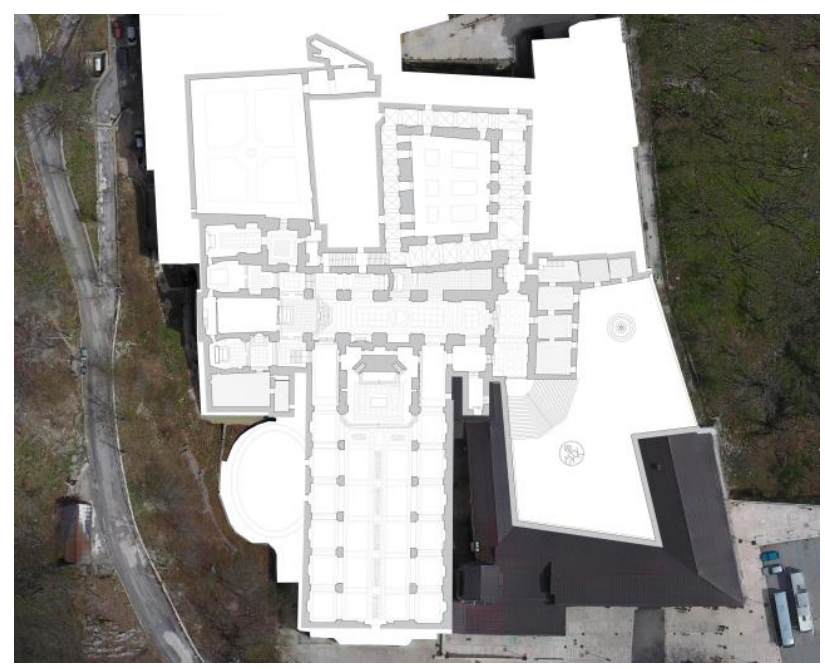

Figure 15. Combination of planimetric drawings

The construction of this basic documentation include as future developments subsequent thematizations for the realization of 3D geometric models where on the basis of the latter, a first evaluation of hypotheses on the spatial configuration of the different historical periods that characterized the complex will be undertaken (where obviously possible) with the integration of iconographic sources.

\section{CONCLUSIONS}

This paper presented the partial results of a planned cognitive activity that is expressed through the integration of digital survey technologies (Russo et al, 2014). The scientific community has long shown an interest in the integration of $3 \mathrm{D}$ reality-based survey technologies. Among the aspects to be taken into account when integrating data from different types of sensors (Beraldin, 2004), there is undoubtedly the will to reduce to a minimum the uncertainties on the data acquired, to optimize times, in relation to both the acquisition and processing phases of, and reduce costs, especially of the instruments used, both hardware and software.

The study looked transversally at the different expressions of Cultural Heritage, ranging from the more complex dimension of architecture and its environmental context to that of detail.

The reasons for this kind of research can be found in the desire to experiment and identify a methodology, based on the multiscalar survey realized through the use of multi-sensors.

If the digital technologies adopted now fall within the sphere of tested and consolidated cognitive processes, the will and necessity linked to their integration, invites to optimize their use, which can only be the result of specific and careful considerations, which are also conditioned by the characteristics and typicality of the investigated contexts.

\section{ACKNOWLEDGEMENTS}

The authors would like thank Arch. Marco Facchini, Technical Manager of the mLAB - Monitoring Laboratory of the Department of Architecture of the University of Naples Federico II, for his support in taking the aerial photographs and videos.

\section{REFERENCES}

Angás, J., Uribe, P., Ariño, E., Gurt, J. M., Martínez-Ferreras, V., and Pidaev, S.: A Multi-Scalar photogrammetric recording approach in Termez (Uzbekistan), Int. Arch. Photogramm. Remote Sens. Spatial Inf. Sci., XLII-2/W15, 93-100, https://doi.org/10.5194/isprs-archives-XLII-2-W15-93-2019, 2019.

Bastonero, P., Donadio, E., Chiabrando, F., and Spanò, A.: Fusion of $3 D$ models derived from TLS and image-based techniques for $\mathrm{CH}$ enhanced documentation, ISPRS Ann. Photogramm. Remote Sens. Spatial Inf. Sci., II-5, 73-80, https://doi.org/10.5194/isprsannals-II-5-73-2014, 2014.

Beraldin, J.-A. 2004. Integration of laser scanning and closerange photogrammetry the last decade and beyond. Proc. IAPRS 35, 5, 972--983.

Callieri, M., Chica, A., Dellepiane, M., Besora, I., Corsini, M., Moyés, J., Ranzuglia, G., Scopigno, R., Brunet, P. 2011. Multiscale acquisition and presentation of very large artifacts: The case of Portalada. In Journal on Computing and Cultural Heritage (JOCCH), vol. 3, n. 4, pp. 1-14.

Dominici, D., Alicandro, M., Rosciano, E., and Massimi, V.: Multiscale documentation and monitoring of L'Aquila historical centre using uav photogrammetry, Int. Arch. Photogramm. Remote Sens. Spatial Inf. Sci., XLII-5/W1, 365371, https://doi.org/10.5194/isprs-archives-XLII-5-W1-3652017, 2017. 
Farella, E. M., Torresani, A., and Remondino, F.: SPARSE POINT CLOUD FILTERING BASED ON COVARIANCE FEATURES, Int. Arch. Photogramm. Remote Sens. Spatial Inf. Sci., XLII-2/W15, 465-472, https://doi.org/10.5194/isprsarchives-XLII-2-W15-465-2019, 2019.

Grilli, E., Farella, E. M., Torresani, A., and Remondino, F.: Geometric features analysis for the classification of Cultural Heritage Point Clouds, Int. Arch. Photogramm. Remote Sens. Spatial Inf. Sci., XLII-2/W15, 541-548, https://doi.org/10.5194/isprs-archives-XLII-2-W15-541-2019, 2019.

Inzerillo, L., Santagati, C., Di Paola, F.: Ricostruzione di una scena urbana $3 D$ utilizzando VisualSfM.. DISEGNARECON, [S.1.], p. XIX / 1-8, ott. 2013. ISSN 1828-5961.

Lo Brutto, M. and Spera, M. G.: IMAGE-BASED AND RANGEBASED $3 D$ MODELLING OF ARCHAEOLOGICAL CULTURAL HERITAGE: THE TELAMON OF THE TEMPLE OF OLYMPIAN ZEUS IN AGRIGENTO (ITALY), Int. Arch. Photogramm. Remote Sens. Spatial Inf. Sci., XXXVIII-5/W16, 515-522, https://doi.org/10.5194/isprsarchives-XXXVIII-5W16-515-2011, 2011.

Russo, M. and Manferdini, A. M.: Integration of image and range-based techniques for surveying complex architectures, ISPRS Ann. Photogramm. Remote Sens. Spatial Inf. Sci., II-5, 305-312, https://doi.org/10.5194/isprsannals-II-5-305-2014, 2014. 